\title{
Comparison of captopril and ibopamine in mild to moderate heart failure
}

\author{
H J M Dohmen, P H J M Dunselman, P A Poole-Wilson
}

\begin{abstract}
Objective-To determine the effects of ibopamine $100 \mathrm{mg}$ three times daily compared with captopril $25 \mathrm{mg}$ three times daily on exercise capacity in patients with
\end{abstract} chronic heart failure.

Design-A randomised, double blind, parallel group comparison of the addition of ibopamine versus captopril during a period of 24 weeks.

Setting-26 outpatient cardiology clinics in seven European countries.

Patients-266 patients, with mild to moderate chronic heart failure (New York Heart Association (NYHA) functional class II, 81\% and III, 19\%) and evidence of an enlarged left ventricle. Patients received concomitant treatment with diuretics and/or digitalis.

Main outcome measure-Exercise duration after 24 weeks of treatment, compared with baseline.

Results-Mean (SD) ejection fraction was $29(8) \%$ and the baseline exercise duration in the captopril and ibopamine groups 665 (160) and 675 (174) seconds, respectively. At the end of the study, exercise duration had improved in both groups, by $29 \mathrm{sec}-$ onds in the ibopamine group $(P<0.01)$, and by 24 seconds in the captopril group $(P<0.05)$. There was no difference between groups $(P=0.69,95 \%$ confidence interval -22 to 33 ). NYHA class, signs and symptoms score, and dyspnoea and fatigue index improved equally in both groups. The total number of adverse events was the same in both treatment groups, but gastrointestinal complaints occurred more often in the ibopamine group. The number of patients with premature withdrawals was no different.

Conclusions-No difference was detected between the effect of captopril and ibopamine on exercise time in patients with mild to moderate heart failure during a treatment period of 24 weeks.

(Heart 1997;78:285-290)

Keywords: ibopamine; captopril; heart failure; clinical trials

Left ventricular dysfunction with signs and symptoms of congestive heart failure is associated with haemodynamic and neurohumoral abnormalities. ${ }^{1}$ The angiotensin converting enzyme (ACE) inhibitors have a beneficial effect on the haemodynamic consequences of heart failure, partly by reducing preload and afterload of the failing heart, resulting in an increase of cardiac output. The impact on the renin-angiotensin-aldosterone system results in less sodium and water retention. The ACE inhibitors are considered, with diuretics, to be the conventional treatment for congestive heart failure. ${ }^{23}$ Ibopamine is an orally active dopamine agonist with beneficial haemodynamic and neurohumoral properties. After ingestion, ibopamine is hydrolysed to epinine (N-methyldopamine) which activates dopamine receptors. At a dosage of $300 \mathrm{mg}$ daily, the activation of dopamine receptors results in vasodilatation without any positive inotropic action. ${ }^{4} \mathrm{~A}$ reduction in plasma noradrenaline concentrations after ibopamine has been documented in heart failure patients. ${ }^{56}$ In clinical studies in patients with mild to moderate congestive heart failure, ibopamine was well tolerated and effective in comparison with placebo, digoxin, and diuretics. ${ }^{7-9} \mathrm{We}$ report the results of a prospective, randomised, parallel, double blind study designed to compare the effects of 24 weeks of treatment with either ibopamine or the ACE inhibitor captopril.

\section{Methods}

The study was a double blind, randomised, parallel group comparison of captopril $(25 \mathrm{mg}$ three times daily) and ibopamine (100 mg three times daily), in patients with stable, mild to moderate congestive heart failure (New York Heart Association (NYHA) class II and III). The study was conducted in 26 centres in seven European countries (see appendix). After a washout period of at least one week, a placebo run in period of two weeks was followed by a double blind treatment period of 24 weeks with captopril ( $25 \mathrm{mg}$ three times daily) or ibopamine (100 $\mathrm{mg}$ three times daily) in addition to baseline treatment with diuretics, digitalis or both. Patients were randomly assigned to each treatment arm in a ratio of $1: 1$.

The protocol was approved by the ethics committee of each participating centre and was conducted in accordance with the Declaration of Helsinki. All patients gave their written informed consent.

\section{PATIENTS}

Male and female patients, aged between 20 and 79 years with mild to moderate heart failure (NYHA class II and III) of at least three months' duration, on background treatment with diuretics or digitalis or both were 
selected. A myocardial abnormality had to be documented by at least one of the following criteria:

(1) Left ventricular ejection fraction at rest $<40 \%$ as measured by cineangiography, radionuclide ventriculography, or cross sectional echocardiography, within three months of the start of the study.

(2) Cardiothoracic ratio $>0.52$ on chest $x$ ray.

(3) Ventricular internal end diastolic diameter of $>54 \mathrm{~mm}$, measured by echocardiography.

Patients were excluded from participation if they had heart failure due to haemodynamically significant valvar disease, active myocarditis, thyroid disease, or hypertrophic obstructive cardiomyopathy. Further exclusion criteria were ventricular or supraventricular arrhythmias not satisfactorily controlled by appropriate antiarrhythmic treatment; hypertension (diastolic blood pressure above $110 \mathrm{~mm} \mathrm{Hg}$, or systolic blood pressure above $180 \mathrm{~mm} \mathrm{Hg}$, or both); a pacemaker; serum creatinine $>2.5 \mathrm{mg} / \mathrm{dl}(250 \mu \mathrm{mol} / \mathrm{l})$; proteinuria $>500 \mathrm{mg} / 24 \mathrm{~h}$; renal artery stenosis; significant hepatic disorders (aspartate aminotransferase or alanine aminotransferase of more than two times the upper limit of normal); significant anaemia (haemoglobin less than $110 \mathrm{~g} / \mathrm{d}$ ); leucopenia (white blood count less than $3500 / \mathrm{mm}^{3}$ ); or uncontrolled diabetes mellitus. Prohibited medications were monoamine oxidase inhibitors, phenothiazines, dopaminergic and antidopaminergic agents, $\beta$ blockers, long acting nitrates, calcium channel blockers, vasodilators, other inotropic agents, and spironolactone. Treatment with angiotensin converting enzyme (ACE) inhibitors, if relevant, was discontinued at least three weeks before the screening period. Patients with a previous history of intolerance to either captopril or ibopamine were excluded.

\section{STUDY DESIGN}

After screening in the outpatient clinic, the study started with a washout period of any prohibited medication of at least seven days, during which the clinical stability of each patient was confirmed, and routine laboratory and bicycle ergometry exercise tests were performed. Patients who had never been treated with ACE inhibitors received a pretest dose of $6.25 \mathrm{mg}$ captopril before randomisation. If at 90 minutes, systolic blood pressure was below $85 \mathrm{~mm} \mathrm{Hg}$ the patient was not included. When eligibility was confirmed and written informed consent obtained, patients received single blind placebo for two weeks, after which they performed the baseline exercise test. The patients then entered the 24 week study period during which ibopamine $100 \mathrm{mg}$ three times daily or captopril $25 \mathrm{mg}$ three times daily was given in a double blind, double dummy fashion. Diuretics and digoxin were to be continued at the same dosage throughout the study period. Patients were instructed to take their medication three times daily at fixed times. At the start of the study, and during follow up visits at 4,12 , and 24 weeks, a physical examina- tion and exercise tests were performed, and routine laboratory investigations undertaken. At each visit the functional class (NYHA) was determined, and severity of heart failure was assessed by a standard heart failure score (signs and symptoms), ${ }^{6}$ and a dyspnoea/fatigue index score. ${ }^{10}$

In selected centres, a venous blood sample was drawn for the determination of plasma neurohormones (noradrenaline, aldosterone, atrial natriuretic factor, arginine-vasopressin, and renin), at the start and at the end of the study. Blood was collected after 30 minutes of supine rest before the exercise test was performed. All blood samples were analysed in a central core laboratory (Winchester Research Laboratories, Essex, UK). A 24 hour Holter ECG recording was made at the start and at the end of the study in selected centres. The tapes were analysed in a central core laboratory for a substudy analysis of heart rate variability (Cardio Data System, Cambridgeshire, UK). Data are to be reported separately. All adverse events were documented.

\section{EXERCISE TESTS}

Exercise tests were performed at screening, at the end of the washout period, at randomisation after a two week single blind placebo treatment, and at 4,12 and 24 weeks after start of active treatment. All exercise tests were performed at the same time of the day. The test started with unloaded pedalling for three minutes at a rate of $60 \mathrm{rpm}$., then three minutes at $20 \mathrm{~W}$, followed by an increase in work load with $30 \mathrm{~W}$ every three minutes. Blood pressure was measured before the start of exercise, during the last 30 seconds of every exercise stage and three minutes after exercise. The electrocardiogram was monitored continuously during exercise and recovery. Eligibility criteria resulting from the exercise test were the ability to maintain a cycle speed of at least $55 \mathrm{rpm}$ for more than six minutes. Patients with a ST segment depression of more than $3 \mathrm{~mm}$, supraventricular tachycardia (with a heart rate of more than 180 beats/min), ventricular tachycardia (a run of more than three ventricular premature contractions), a fall in arterial pressure of $>15 \mathrm{~mm} \mathrm{Hg}$, or a rise in systolic pressure exceeding $240 \mathrm{~mm} \mathrm{Hg}$ were not eligible.

\section{STATISTICAL METHODS}

The primary endpoint of the study was duration of exercise. Secondary endpoints included NYHA classification, clinical signs and symptoms, fatigue and dyspnoea index scale, and changes in neurohormones. All data were evaluated by intention to treat principle, carrying forward the last observed value in case of withdrawals or missing values. Thereby only patients without any observation after randomisation were excluded from analysis. For each patient, the response to the treatment was measured as change from baseline, and the means calculated in the two groups compared by a $t$ test for independent samples. Treatment differences were calculated with a $95 \%$ confidence interval (CI). A within group 
Table 1 Baseline characteristics of the two treatment groups: means (SD) for continuous variables, frequencies and (\%) for categorical variables

\begin{tabular}{|c|c|c|}
\hline & $\begin{array}{l}\text { Ibopamine } \\
(n=130)\end{array}$ & $\begin{array}{l}\text { Captopril } \\
(n=136)\end{array}$ \\
\hline $\begin{array}{l}\text { Age (years) } \\
\text { Sex (male/female) }\end{array}$ & $\begin{array}{l}61 \cdot 8(8 \cdot 0) \\
113 / 17\end{array}$ & $\begin{array}{l}61 \cdot 6(9 \cdot 3) \\
111 / 25\end{array}$ \\
\hline \multicolumn{3}{|l|}{ Vital signs } \\
\hline Weight $(\mathrm{kg})$ & $76 \cdot 5(13 \cdot 1)$ & $77 \cdot 0(10 \cdot 8)$ \\
\hline Systolic blood pressure (mm Hg) & $132 \cdot 1(19 \cdot 4)$ & $133.4(19.8)$ \\
\hline Diastolic blood pressure (mm Hg) & $80 \cdot 2(9 \cdot 4)$ & $81.5(10.0)$ \\
\hline Heart rate (beats $/ \mathrm{min}$ ) & $80 \cdot 0(14 \cdot 2)$ & $80 \cdot 2(15 \cdot 2)$ \\
\hline \multicolumn{3}{|l|}{ Signs of heart failure } \\
\hline Left ventricular ejection fraction & $28 \cdot 6(7 \cdot 0)$ & $30.4(9 \cdot 2)$ \\
\hline $\mathrm{LV}$ end diastolic diameter ( $\mathrm{mm})$ & $66(6 \cdot 0)$ & $64(6 \cdot 0)$ \\
\hline CTR ( $x$ ray) & $0.53(0.05)$ & $0.53(0.07)$ \\
\hline Signs and symptoms score & $7 \cdot 0(1 \cdot 8)$ & $7 \cdot 1(1 \cdot 7)$ \\
\hline Dyspnoea/fatigue index & $6.7(1.8)$ & $6.5(1.7)$ \\
\hline \multicolumn{3}{|l|}{ Aetiology of heart failure } \\
\hline Ischaemic & $89(68 \cdot 5)$ & $88(64 \cdot 7)$ \\
\hline Idiopathic & $34(26 \cdot 1)$ & $39(28 \cdot 6)$ \\
\hline Hypertensive & $7(5 \cdot 4)$ & $9(6 \cdot 6)$ \\
\hline Previous myocardial infarction & $84(64 \cdot 6)$ & $72(52 \cdot 9)$ \\
\hline \multicolumn{3}{|l|}{ ECG at rest (12 lead) } \\
\hline Atrial fibrillation & $18(15 \cdot 0)$ & $21(16 \cdot 5)$ \\
\hline Diabetes & $11(8 \cdot 5)$ & $10(7 \cdot 4)$ \\
\hline \multicolumn{3}{|l|}{ NYHA functional class } \\
\hline II & $105(80 \cdot 7)$ & $110(80 \cdot 8)$ \\
\hline III & $25(19 \cdot 3)$ & $26(19 \cdot 2)$ \\
\hline \multicolumn{3}{|l|}{ Exercise duration } \\
\hline Seconds (SD) & $675 \cdot 2(174 \cdot 2)$ & $665 \cdot 0(159 \cdot 9)$ \\
\hline Range & 302 to 1071 & 385 to 1226 \\
\hline \multicolumn{3}{|l|}{ Concomitant drug treatment } \\
\hline Diuretics in $\mathrm{N}$ patients (\%) & $104(80 \cdot 0 \%)$ & $106(77.9 \%)$ \\
\hline Digitalis in $\mathrm{N}$ patients (\%) & $62(47 \cdot 7 \%)$ & $69(50 \cdot 7 \%)$ \\
\hline Antiarrhythmic drugs (\%) & $14(10 \cdot 7 \%)$ & $10(7 \cdot 3 \%)$ \\
\hline \multirow{6}{*}{$\begin{array}{l}\text { Neurohormones } \\
\text { (measured in patients) } \\
\text { Noradrenaline }(\mathrm{pg} / \mathrm{ml}) \\
\text { Aldosterone }(\mathrm{pg} / \mathrm{ml}) \\
\text { ANF }(\mathrm{pg} / \mathrm{ml}) \\
\text { Arginine vasopressin }(\mathrm{pg} / \mathrm{ml}) \\
\text { Renin }(\mathrm{ng} / \mathrm{ml} / \mathrm{h})\end{array}$} & & \\
\hline & 62 & 69 \\
\hline & $\begin{array}{l}499 \cdot 4(240 \cdot 9) \\
133.8(97 \cdot 5)\end{array}$ & $\begin{array}{l}533 \cdot 3(287 \cdot 6) \\
171.5(227 \cdot 3)\end{array}$ \\
\hline & $44 \cdot 3(36 \cdot 8)$ & $42 \cdot 7(33 \cdot 8)$ \\
\hline & $0.84(0.68)$ & $0.97(0.94)$ \\
\hline & $8 \cdot 3(8 \cdot 7)$ & $10.6(16.9)$ \\
\hline
\end{tabular}

LV, left ventricular; CTR, cardiothoracic ratio; NYHA, New York Heart Association; ANF, atrial natriuretic factor.

analysis was also performed. All tests were two tailed, with significance at an $\alpha$ level of 0.5 .

\section{STUDY ORGANISATION}

Two committees were appointed to manage the study: a steering committee responsible for the scientific issues and an independent safety committee responsible for safety issues. Members are listed in the appendix.

\section{Results}

The number of patients randomised in 26 centres from seven European countries was 266: 130 to ibopamine treatment and 136 to captopril treatment. Randomisation resulted in groups that were well balanced for both demographics and disease related variables (table 1).

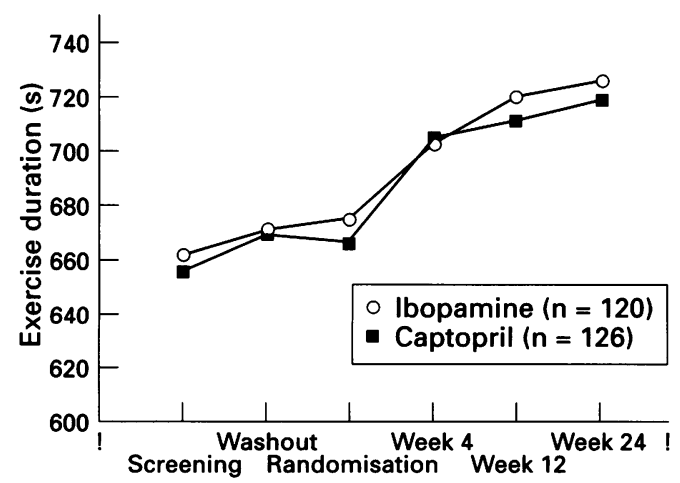

Mean exercise duration in seconds. No significant differences between the treatment groups in the three tests before or during active treatment. Within group analysis of changes after 24 weeks $\mathrm{v}$ randomisation: ibopamine group $P<0.01$; captopril group $P<0.05$.
Among the 266 randomised patients, 200 completed the 24 week treatment as per protocol (92 ibopamine, 108 captopril), and 66 were withdrawn before week $24,38 / 130$ $(29 \%)$ in the ibopamine arm, and $28 / 136$ (21\%) in the captopril arm $(P=0 \cdot 11)$. The most common reason for discontinuation from the study was an adverse event, reported as the main reason for 47 patients.

Twenty patients, 10 in each group, were withdrawn before week 4, without any assessment after randomisation. Thus the evaluable population was 246 patients, 120 in the ibopamine arm and 126 in the captopril arm. All results described refer to these patients, unless explicit reference is made to different subsets.

\section{EFFECTS ON EXERCISE CAPACITY}

Exercise times of all 246 evaluable patients are shown in the figure. Differences between the groups at screening, at the end of the washout period, and at randomisation were small. Between randomisation and week 4, mean (SD) exercise time increased from 675 (174) to 703 (164) seconds in the ibopamine group, and from 666 (160) to 705 (173) seconds in the captopril group. Analysis using the carry forward principle showed a mean (SD) difference from baseline to week 12 and week 24, of 28 (85), and 29 (100) seconds in the ibopamine group $(n=120$, both $P<0.01)$, and 22 (106) and 24 (115) seconds in the captopril group ( $n=126$, both $P<0.05)$. Analysis of changes in exercise time from baseline to week 24 revealed a statistically non-significant difference between the two groups of $5.4(108.0)$ seconds, $\mathrm{P}=0.69 ; 95 \% \mathrm{CI}-21.9$ to $32 \cdot 7$. The same analysis carried out in all patients who completed the 24 week treatment period revealed a similar pattern, with a difference from baseline to 24 weeks in exercise duration of $32.9(107.7)$ seconds in the ibopamine group $(n=92)$ and $33.7(110.4)$ seconds in the captopril group $(n=108)$.

The results were unaltered if all 266 patients were analysed using the carry forward principle.

\section{EFFECTS ON NYHA CLASS}

The mean (SD) functional class at the start of the study did not differ between groups, being $2.57(0.22)$ in the ibopamine group, and 2.56 $(0 \cdot 20)$ in the captopril group (table 2). After 24 weeks of treatment the functional class improved in both groups. The improvement in the ibopamine group was $0.29 \quad(0.39)$, $P<0.001$, and in the captopril group 0.24 $(0.38), P<0.001$. There was no significant between group difference $(P=0.31 ; 95 \% \mathrm{CI}$ $-0 \cdot 14$ to $0 \cdot 04$ ).

\section{EFFECTS ON SIGNS AND SYMPTOMS TOTAL} SCORE

Total score of signs and symptoms was obtained by adding the single scores observed in orthopnoea, dyspnoea, peripheral oedema, and fatigue (table 2). Mean (SD) values at randomisation were $7.0(1.75)$ in the ibopamine group and $6.96(1.52)$ in the capto- 
Table 2 Effects on symptoms of captopril and ibopamine; mean (SD) of New York Heart Association (NYHA) classification (score), signs and symptoms (score), and dyspnoea and fatigue index (score); comparison of values after 24 weeks of treatment $v$ randomisation (baseline)

\begin{tabular}{|c|c|c|c|}
\hline & $\begin{array}{l}\text { NYHA } \\
\text { class }\end{array}$ & Signs and symptoms & $\begin{array}{l}\text { Dyspnoea and } \\
\text { fatigue index }\end{array}$ \\
\hline $\begin{array}{l}\text { Ibopamine } \\
\text { Baseline } \\
\text { 24 weeks } \\
\text { P value within group }\end{array}$ & $\begin{aligned} & 2.57(0.22) \\
& 2.28(0.43) \\
< & 0.001\end{aligned}$ & $\begin{aligned} & 7.00(1.75) \\
& 6.40(1.91) \\
< & 0.001\end{aligned}$ & $\begin{aligned} & 6.66(1.79) \\
& 7.30(1.97) \\
< & 0.001\end{aligned}$ \\
\hline $\begin{array}{l}\text { Captopril } \\
\text { Baseline } \\
24 \text { weeks } \\
\text { P value within group } \\
\text { P value between groups }\end{array}$ & $\begin{aligned} & 2.56(0.20) \\
& 2.32(0.38) \\
< & 0.001 \\
& 0.31\end{aligned}$ & $\begin{aligned} & 6.96(1.52) \\
& 6.43(1.67) \\
&< 0.001 \\
& 0.61\end{aligned}$ & $\begin{array}{l}6.65(1.69) \\
7.43(1.97) \\
<0.001 \\
0.49\end{array}$ \\
\hline
\end{tabular}

pril group. After 24 weeks of treatment there was a change in the ibopamine group of -0.60 $(1.64), P<0.001$, and in the captopril group of $-0.53(1.59), P<0.001$. Between group comparison of changes revealed no significant differences $(\mathrm{P}=0.71 ; 95 \% \mathrm{CI}-0.48$ to 0.32$)$.

EFFECTS ON DYSPNOEA AND FATIGUE INDEX Baseline data were practically identical in the two groups, at $6 \cdot 7(1 \cdot 7)$ (table 2$)$. There was a significant change at 24 weeks in both groups, of $0.64(1.74), P<0.001$, in the ibopamine group, and $0.79(1.54), P<0.001$, in the captopril group. Between group differences were not significant: $0.144(1.64), P=0.49(95 \%$ $\mathrm{CI}-0.55$ to $0 \cdot 26$ ).

\section{EFFECTS ON NEUROHORMONES}

In $62 / 120$ patients $(52 \%)$ in the ibopamine group and in $69 / 126$ patients $(55 \%)$ in the captopril group neurohormones were determined at randomisation and after 24 weeks of treatment. Plasma noradrenaline was not modified by treatment (ibopamine group $-18.8 \mathrm{pg} / \mathrm{ml}$; captopril group $-21.6 \mathrm{pg} / \mathrm{ml}$ ). Plasma aldosterone changed little in the ibopamine group $(-1.92(102 \cdot 1) \mathrm{pg} / \mathrm{ml})$ but decreased in the captopril group $(-57 \cdot 2$ $(138.0) \mathrm{pg} / \mathrm{ml} ; \mathrm{P}$ value between the groups $<0.02)$. Plasma renin activity decreased in the ibopamine group $(-0.55(8.89) \mathrm{pg} / \mathrm{ml})$ and increased markedly with ACE inhibition in the captopril group $(+15.94(27.34) \mathrm{pg} / \mathrm{ml} ; \mathrm{P}$ value between the groups $<0.001)$. Atrial natriuretic factor was modified similarly by both treatments, with a decrease of -16.5 $(41.14) \mathrm{pg} / \mathrm{ml}$ in the ibopamine group and $-13.6(41.07) \mathrm{pg} / \mathrm{ml}$ in the captopril group

Table 3 Adverse events

\begin{tabular}{lccc}
\hline & Ibopamine & Captopril & Total \\
\hline Number of patients & 130 & 136 & 266 \\
At least one adverse event & $77(59 \cdot 2 \%)$ & $74(54 \cdot 5 \%)$ & 151 \\
At least one serious adverse event & $13(10 \cdot 0 \%)$ & $17(12 \cdot 5 \%)$ & 30 \\
Body system & & & \\
Body as a whole & $34(26 \cdot 2 \%)$ & $24(17 \cdot 6 \%)$ & 58 \\
Digestive & $37(28 \cdot 5 \%)$ & $12(8 \cdot 8 \%)$ & $49 \star$ \\
Cardiovascular & $21(16 \cdot 2 \%)$ & $24(17 \cdot 6 \%)$ & 45 \\
Respiratory & $14(10 \cdot 8 \%)$ & $24(17 \cdot 6 \%)$ & 38 \\
Nervous & $6(4 \cdot 6 \%)$ & $10(7 \cdot 4 \%)$ & 16 \\
Skin, appendages & $4(3 \cdot 1 \%)$ & $8(5 \cdot 9 \%)$ & 12 \\
Special senses & $2(1 \cdot 5 \%)$ & $5(3 \cdot 7 \%)$ & 7 \\
Metabolic disorders & $2(1 \cdot 5 \%)$ & $3(2 \cdot 2 \%)$ & 5 \\
Urogenital & $2(1 \cdot 5 \%)$ & $3(2 \cdot 2 \%)$ & 5 \\
Musculoskeletal & $1(0 \cdot 8 \%)$ & $0(0 \%)$ & 1 \\
Haematological & 0 & $2(1 \cdot 5 \%)$ & 2 \\
\hline
\end{tabular}

Adverse events during the 24 week treatment period. No differences between ibopamine and captopril, except for digestive body system $\left({ }^{\star} \mathrm{P}<0.001\right)$. (within group, both $\mathrm{P}<0.02$; between group, $P=0.68$ ). The arginine vasopressin activity was modified to the same extent in both groups: ibopamine $-0.26(0.84) \mathrm{pg} / \mathrm{ml}$; captopril $-0.27(1.03) \mathrm{pg} / \mathrm{ml}$ (within group, both $P<0.05$; between group, $P=0.96)$.

\section{ADVERSE EVENTS}

Of the 266 patients, 151 experienced one or more adverse events (table 3), 77/130 (59\%) in the ibopamine group and 74/136 (54\%) in the captopril group. Out of these, 13/130 patients $(10 \%)$ in the ibopamine group and $17 / 136(12.5 \%)$ in the captopril group experienced a serious adverse event, leading in most cases to withdrawal. The reasons for premature termination of the study were:

(1) Clinical deterioration of heart failure, requiring prohibited drugs or open treatment with ACE inhibitors;

(2) Severe angina;

(3) Other serious adverse events.

The incidence of adverse events did not differ between the groups, apart from gastrointestinal complaints. The incidence of these complaints in the ibopamine group was $37 / 130(28.5 \%)$, and in the captopril group, $12 / 136(8 \cdot 8 \%), P<0.001$. Coughing was present in both treatment groups, in the ibopamine group in $6 / 130$ patients $(4.6 \%)$ and in the captopril group in $12 / 136$ patients $(8 \cdot 8 \%)$.

The reasons for withdrawal in both groups were mainly adverse events. Gastrointestinal complaints were more often a reason for withdrawal in the ibopamine group than in the captopril group (13 $v 5$ patients, $\mathrm{P}<0.05$ ). Withdrawal because of progression of heart failure was not significantly different (10 ibopamine $v 7$ captopril). Abnormalities of laboratory data did not lead to withdrawals.

\section{MORTALITY}

Four patients died during the whole study period ( 24 plus 2 weeks). One patient in the ibopamine group died suddenly after 70 days of treatment. The patient, a woman of 65 years, was found dead at home early in the morning. Three patients died in the captopril group. Two patients, a woman of 63 years, 15 days after enrolment, and a man of 78 years, 60 days after enrolment, died suddenly. The third patient of the captopril group, a 79 year old man, died 12 days after having been withdrawn from the study because of progression of heart failure, during open treatment with captopril and amiodarone.

\section{Discussion}

The results show that blockade of the reninangiotensin-aldosterone system with captopril resulted in the same modest increase in exercise duration as direct dopamine receptor activation by the metabolite of ibopamine, epinine. The results are similar to those from a previous comparative study of ibopamine and captopril in a smaller group of elderly patients. ${ }^{11}$ They are also consistent with the results of other studies of captopril or ibopa- 
mine using comparable observation periods. ${ }^{612}$

Neurohumoral modulation of the activated neurohumoral systems is one of the goals in treatment of patients with chronic heart failure. ${ }^{13}$ The differences and similarities of the effects on neurohormones after long term treatment with captopril and ibopamine are therefore of special interest. Plasma noradrenaline was increased only moderately at baseline, and was not influenced by either treatment. Atrial natriuretic factor and arginine vasopressin were increased slightly at baseline, but decreased to normal values in both treatment groups. The significant increase in plasma renin activity, and the substantial decrease in plasma aldosterone with captopril, reflects the pharmacological activity of this drug on the renin-angiotensin-aldosterone system, which is not unfavourably influenced by ibopamine. Apart from the characteristic effect of the ACE inhibitor on renin and aldosterone, the results of the effects on neurohormones of long term treatment of captopril and ibopamine are similar, in concordance with the results on exercise duration. However, they are to be interpreted with caution in the light of the high variability observed.

At the time this study was designed, a placebo arm only treated with diuretics and digoxin in a study of patients with documented symptomatic heart failure was considered to be inappropriate because of the known benefit of ACE inhibitors. Ibopamine and captopril were therefore not compared with placebo. The three exercise tests performed before the start of active treatment did not reveal a training effect, and the increase in exercise tolerance during active treatment was similar to results of placebo controlled studies with ACE inhibitors. ${ }^{12} 1415$

ACE inhibition has been shown to be beneficial in the management of heart failure of any severity. ${ }^{16-18}$ Although ACE inhibitors are, with diuretics, considered to be the cornerstone in the treatment of heart failure, many patients have unwanted side effects or are intolerant of these drugs.

Ibopamine has been considered as a possible alternative for ACE inhibitors, being a safe and effective drug for heart failure patients, both as monotherapy, ${ }^{719}$ and as comedication. ${ }^{6}$ Recently, the results of the PRIME II (prospective randomised study of ibopamine on mortality and efficacy) study have been presented, in which ibopamine was added to treatment with ACE inhibitors and diuretics in patients with severe heart failure (NYHA grades III and IV). ${ }^{20} \mathrm{~A}$ higher mortality was found in the ibopamine group compared to placebo. This effect was apparent after six months of treatment. The higher mortality appeared to be clustered in the subgroup of more severe patients in the ibopamine group, while no differences in mortality were observed in the subgroup of patients with less advanced heart disease. In our study no difference between captopril and ibopamine with respect to outcomes was found. Serious adverse events-progression to more severe heart failure, proarrhythmia, and sudden death-were not different from captopril. The effect of ibopamine in mild to moderate heart failure may be different from its effect in severe heart failure, although our study, in contrast to the PRIME II study, was not designed as an outcome trial.

The results from our study lead to the conclusion that ibopamine and captopril have similar effects on exercise time when used in the treatment of mild to moderate heart failure over a period of 24 weeks.

\section{Appendix}

THE STUDY ORGANISATION AND PARTICIPATING CENTRES

Clinical investigators
United Kingdom
J Conway (Oxford)
S Holmerg (Brighton)
S O Banim (London)
B A Gould (Sidcup)
A R Lorimer (Glasgow)
A H Gershlick (Leicester)
Italy
B Trimarco (Naples)
A Gavazzi (Pavia)
G Binaghi (Varese)
The Netherlands (Working Gro

The Netherlands (Working Group on Cardiovascular Research, WCN)

P H J M Dunselman (Breda)

H J M Dohmen ('s Hertogenbosch)

H Groeneveld (Deventer)

C J Poortermans (Enschede)

J A Kragten (Heerlen)

N J Holwerda, W H Pasteuning (Tilburg)

W G de Voogt (Amsterdam)

A Bosma (Veldhoven)

P J L M Bernink (Groningen)

L $\mathrm{H} J$ van Kempen (Arnhem)

Spain

J M Aguirre (Bilbao)

A del Rio Ligorit (Zaragoza)

France

J P Bounhoure (Toulouse)

J Kayanakys (Biarritz)

A Sacrez (Strasbourg)

Belgium

$\mathrm{F}$ van de Werf (Leuven)

Switzerland

T Moccatti (Lugano)

Steering committee

P A Poole-Wilson, chairman (UK)

H J M Dohmen (The Netherlands)

J Lopez Sendon (Spain)

B A Gould (UK)

B Trimarco (Italy)

C Morisco (Italy)

J P Bounhoure (France)

Critical events committee

J Ball (UK)

E Marubini (Italy)

R Bonelli (Italy)

Core laboratory for plasma neurohumoral determinations

Winchester Research Laboratories, Essex (UK)

Holter ECG core laboratory

Cardio Data System, Cambridgeshire (UK)

Sponsor

Zambon Group, SpA, Bresso (Milan), Italy

1 Packer M. How should physicians view heart failure? The philosophical and physiological evolution of three conceptual models of the disease. Am f Cardiol 1993;71: 3-11C.

2 Grinstead WC, Francis MJ, Marks GF, Tawa CB, Zoghbi WA, Young JB. Discontinuation of chronic diuretic therapy in stable congestive heart failure secondary to coronary artery disease or to idiopathic dilated cardio- 
ment of heart failure. N Engl f Med 1991;325:351-3.

4 Henwood JM, Todd PA. Ibopamine: a preliminary review of its pharmacodynamic and pharmacokinetic properties and therapeutic efficacy. Drugs 1988;36:11-31.

5 Rousseau MF, Raigoso J, van Eyll C. Effects of intravenous epinine administration on left ventricular systolic performance, coronary hemodynamics, and circulating catecholamines in patients with heart failure. 7 Cardiovasc Pharmacol 1992;19:155-62.

6 van Veldhuisen DJ, Man in 't Veld AJ, Dunselman PHJM, Lok DJA, Dohmen HJM, Poortermans JC, et al. Doubleblind placo controlled study of ibopamine and digoxin in plate in patients with mild to moderate heart failure. results of the Dutch Ibopamine Coll Cardiol 1993;22:1564-73.

Cavalli A, Riva E, Schleman M, Abbondati G, Fuccella LM. Ibopamine as a substitute for digitalis in patients on chronic digoxin therapy. Int $\mathcal{F}$ Cardiol 1989;22:381-7.

8 Kleber FX, Thyroff-Friesinger U. Ibopamine versus digoxin in the treatment of mild congestive heart failure. Cardiology 1990;77(suppl 5):75-80.

9 Parker JO, and the Ibopamine Study Group. The effects of oral ibopamine in patients with mild heart failure-a double blind placebo controlled comparison to furosemide. Int $\mathcal{F}$ Cardiol 1993;40:221-7.

10 Feinstein AR, Fisher MB, Pigeon JG. Changes in dyspneafatigue ratings as indicators of quality of life in the treatment of congestive heart failure. Am $\mathcal{f}$ Cardiol 1989;64: 50-5.

11 Barabino A, Galbariggi G, Pizzorni C, Lotti G. Comparative effects of long term therapy with captopril and ibopamine in chronic congestive heart failure in old patients. Cardiology 1991;78:243-56.

12 Captopril Multicenter Research Group. A placebo-controlled trial of captopril in refractory chronic congestive trolled trial of captopril in refractory chronic
heart failure. $7 \mathrm{Am}$ Coll Cardiol 1983;2:755-63.
13 Cohn JN. The prevention of heart failure-a new agenda. $N$ Engl f Med 1992;327:725-7.

14 Erhardt L, MacLean A, Ilgenfritz JP, Gelperin K, Blumenthal M. Fosinopril attenuates clinical deterioration and improves exercise tolerance in patients with heart failure. Eur Heart $\mathcal{f}$ 1995;16:1892-9.

15 Brown EJ, Chew PH, MacLean A, Gelperin K, Ilgenfritz JP, Blumenthal $M$. Effects of fosinopril on exercise tolerance and clinical deterioration in patients with chronic congestive heart failure not taking digitalis. Am $\mathcal{F}$ Cardiol 1995;75:596-600.

16 The CONSENSUS Trial Study Group. Effects of enalapril on mortality in severe congestive heart failure: results of the Cooperative North Scandinavian Enalapril Survival the Cooperative North Scandinavian Enalapril Survival Study (CO

17 The SOLVD Investigators. Effect of enalapril on survival in patients with reduced left ventricular ejection fractions and congestive heart failure. $N \mathrm{Engl} \mathrm{f} \mathrm{Med} \mathrm{1991;325}$ 293-302.

18 Pfeffer MA, Braunwald E, Moye LA. Effect of captopril on mortality and morbidity in patients with left ventricula dysfunction after myocardial infarction: results of the Survival and Ventricular Enlargement Trial. $N$ Engl $f$ Med 1992;327:669-77.

19 van Veldhuisen DJ, Brouwer J, Man in 't Veld AJ, Dunselman PHJM, Boomsma F. Progression of mild untreated heart failure during six months follow-up and clinical and neurohumol effects of ibopamine and monotherapy. Am $\mathcal{I}$ Cardiol 1995;75: 796-800.

20 Hampton JR. Prospective randomised study of ibopamine on mortality and efficacy in heart failure (PRIME II). American College of Cardiology, Orlando, Florida, USA 25 March 1996. 